\title{
Simulasi Under-Voltage Load Shedding dengan Masuknya Integrasi Pembangkit Listrik Tenaga Angin
}

\author{
Wisna Saputri Alfira WS*1, Muhammad Bachtiar Nappu ${ }^{1,2}$, Ardiaty Arief ${ }^{1,2}$ \\ ${ }^{1}$ Departemen Teknik Elektro, Fakultas Teknik, Universitas Hasanuddin \\ Jl. Poros Malino Km.6, Bontomarannu, Gowa, Sulawesi Selatan 92171 \\ ${ }^{2}$ Lembaga Penelitian dan Pengabdian kepada Masyarakat (LP2M), Universitas Hasanuddin \\ Jl. Perintis Kemerdekaan Km.10, Tamalanrea, Makassar, Sulawesi Selatan 90245 \\ *Email: alfirasaputri_19@yahoo.com
}

\begin{abstract}
Abstrak
Simulasi Under Voltage Load Shedding (UVLS) dengan mempertimbangkan integrasi pembangkit listrik tenaga bayu (PLTB). PLTB yang akan diintegrasikan ke dalam sistem interkoneksi Sulawesi Selatan milik PT. PLN (Persero) berada di daerah Sidrap sekitar 70 MW dengan menggunakan 30 turbin angin, menghasilkan 2,5 MW per turbin dan di daerah Jeneponto sekitar 62,5 MW dengan jumlah turbin angin yang sama. Kondisi angin yang berbeda dapat mempengaruhi sistem tenaga yang menyebabkan gangguan besar atau kecil, baik dalam pelepasan generator atau jalur transmisi. Berdasarkan permasalahan ini, penelitian ini bertujuan untuk melakukan simulasi pada daerah yang mengalami jatuh tegangan saat WPP berada di sistem Sulawesi Selatan. Metode sensitivitas dinamis disajikan dalam makalah ini. Dari hasil simulasi dan analisis, diperoleh lokasi load shedding di Makale, Palopo dan Latuppa dapat menstabilkan tegangan sistem namun menyebabkan area Poso berada dalam kondisi over voltage.
\end{abstract}

\section{Abstract}

This paper discusses the simulation of under voltage load shedding (UVLS) by considering the integration of wind power plants (WPP). The WPPs which will be integrated into the Southern Sulawesi interconnection system owned by PT. PLN (Persero) are located in the Sidrap area of approximately $70 \mathrm{MW}$ using 30 wind turbines, generating $2.5 \mathrm{MW}$ per turbine and in the Jeneponto area of about $62.5 \mathrm{MW}$ capacity with the same number of wind turbines. Different wind conditions may affect the power system causing a major or minor disturbance, either in a release of generation or a transmission line. Based on this issue, this study aims to perform a simulation on areas that have voltage collapse when the WPPs are in the Southern Sulawesi system. The method of dynamic sensitivity presented in this paper. From the simulation and analysis results, it is obtained that load shedding locations in Makale, Palopo and Latuppa can stabilize the system's voltage but causing the Poso area to be in an over voltage condition.

Kata-kunci: Wind power plants (WPP), voltage stability, under voltage load shedding (UVLS).

\section{Pendahuluan}

Sistem interkoneksi yang dimiliki oleh PT. PLN (Persero) Wilayah Sulselrabar akan bertambah dengan integrasi PLTB di daerah Sidrap dan Jeneponto. Pembangkit yang akan berintegrasi dengan sistem Sulselrabar merupakan rencana umum penyediaan tenaga listrik (RUPTL) PLN 2010-2019 dimana pada daerah Sidrap sekitar 70 MW dengan menggunakan 30 turbin angin, masing-masing menghasilkan 2.5 MW [1] dan di daerah Jeneponto menghasilkan energi listrik sebesar 62.5 MW dengan 30 turbin angin [2]. Permasalahan yang menjadi dasar pada PLTB adalah kondisi angin yang berubah-ubah tergantung pada keadaan iklim yang terletak pada daerah tersebut. Ketika sumber energi yang dikonversi ke listrik tidak dalam keadaan konstan maka listrik yang dihasilkan tidak juga konstan. Sehingga hal tersebut sangat berpengaruh pada sistem tenaga listrik.

Dalam sistem tenaga listrik skala besar, menjaga kontinuitas dan ketersediaan pasokan listrik untuk para konsumen menjadi tujuan utama pada sistem interkoneksi agar tidak menyebabkan melemahnya stabilitas performa sistem. Referensi [3-5] telah mengidentifikasi stabilitas sistem tenaga sebagai bagian prasyarat terpenting dan terpercaya selama kurang lebih dari 80 tahun terakhir untuk mendapatkan operasi sistem listrik yang aman. Operasi suatu sistem tenaga listrik 
diharapkan dapat mempertahankan stabilitas tegangan yang telah menjadi masalah utama dalam perencanaan dan pengoperasian sistem tenaga [6] dan merupakan bagian penting dalam menjaga ketersediaan suplai listrik secara kontinyu dengan kualitas daya yang baik dengan meminimalisasi terjadinya pemadaman listrik (black out) total atau sebagian.

Ketidakstabilan tegangan merupakan ketidakmampuan sistem untuk mempertahankan profil tegangan dalam batas yang diperbolehkan setelah terjadi gangguan atau perubahan sistem yang dapat membawa sistem jaringan secara keseluruhan untuk kondisi jatuh tegangan yang signifikan [7]. Oleh karena itu, dibutuhkan suatu penanggulan sehingga hal tersebut dapat dihindari. Salah satu cara untuk mempertahankan stabilitas pada tegangan dari sistem dalam kondisi yang tidak diingikan adalah dengan load shedding. Load shedding merupakan metode control prevetif dan ekonomis dalam mengurangi jatuhnya sistem, dimana dilakukan pada lokasi yang tepat sehingga dapat menaikkan tegangan secara signifikan sampai batas nilai toleransi yang diizinkan yaitu $+5 \%$ dan $-10 \%$ dari tegangan nominal [7-9]. Sebagai dasar pedoman untuk mendesain load shedding yang direkomendasikan oleh H. G. Sarmiento, dkk [10]. Oleh karena itu, diperlukan suatu perlakuan untuk memperbaiki penurunan daya reaktif yang mengakibatkan penurunan tegangan, maka dari itu diperlukan perlakuan dengan melakukan under voltage load shedding (UVLS).

UVLS merupakan salah satu penelitian yang kurang banyak menerima perhatian, tetapi seiring dengan berjalannya waktu berbagai metode telah diusulkan untuk UVLS. Awal munculnya konsep UVLS yaitu tahun 1992 oleh Taylor [11] dimana untuk memberikan perlindungan tambahan selain under frequency load sheeding (UFLS) untuk gangguan abnormal di luar kriteria operasi dan perencanaan. Kemudian UVLS semakin berkembang dengan berbagai metode, seperti pada paper [12], dimana metode yang digunakan yaitu menghitung sensitivitas dinamis yang berhubungan dengan gangguan agar sensitivitas lintasan antara tegangan bus dapat dihitung sehingga mendapatkan jumlah yang cukup untuk melakukan pelepasan beban di lokasi yang tepat. Metode lain dari UVLS yaitu dalam sistem tenaga telah di aplikasikan dengan menggabungkan penggunaan generator angin untuk menjaga stabilitas tegangan dengan mempertimbangkan pemodelan beban dinamis dan statis yang melibatkan sebuah algoritma iterasi [13]. Paper ini [3] juga mengaplikasikan UVLS pada 3 mesin 9 bus kemudian dilakukan simulasi dinamis untuk validasi ketahanan dari metode faktor partisipasi bus. Selanjutnya studi ini, melakukan perhitungan nilai Eigen [14] untuk menetapkan tegangan pickup untuk sinyal tripping, dimana nilai Eigen digunakan untuk mengukur indeks global sehingga dapat diketahui jatuhnya tegangan dan besaran tegangan pada bus kritis. Peneliti ini [15] melakukan penelitian yang mempertimbangkan kritis kontigensi untuk optimasi load shedding berdasarkan modal faktor partisipasi. Modal faktor partisipasi dalam penelitian ini digunakan dalam mencari bus yang paling sesuai untuk lokasi load shedding. Referensi [16, 17] telah mengembangkan strategi UVLS dengan model generik beban dinamis. Mendesain skema UVLS memastikan bahwa doubly fed induction generators (DFIG) dapat mengembalikan operasi normal dan tegangan sistem menjadi stabil. Dalam penelitian milik Amraee [18] mengusulkan desain UVLS dengan generator distribusi (DG), namun penelitian ini hanya menggunakan pendekatan analisis tegangan statis dan tidak mempertimbangkan tipe DG. Kelemahan dari teknik tersebut tidak bisa menjelaskan sifat dinamis dari insiden runtuhnya tegangan. Selain itu, dengan pemasangan generator angin dan DGs yang lain, perilaku sistem dinamis dapat mengakibatkan perubahan secara substansial setelah mengalami gangguan karena adanya teknologi DG dan generator konvensional yang berbeda [19].

Dalam tulisan ini, kami mensimulasikan analisis sensitivitas tegangan dinamis dalam merancang skema UVLS untuk menentukan lokasi dan ukuran beban yang harus dikeluarkan jika terjadi gangguan besar pada sistem dengan integrasi WPP ke dalam sistem tenaga Sulawesi Selatan. Kinerja tegangan dinamis dianalisis 
sebelum dan sesudah integrasi WPP Sidrap dan Jeneponto.

\section{Kestabilan Sistem Tenaga Listrik}

Sistem tenaga listrik yang baik adalah sistem yang memenuhi 3 persyaratan dalam pengoperasian yaitu handal dalam menyalurkan energi listrik secara kontinue (reliability), berkualitas dalam menghasilkan besar-besaran standar yang ditetapkan untuk frekuensi dan tegangan (quality) serta stabil (stability) dimana harus segera kembali dalam keadaan normal bila sistem mengalami gangguan.

Kestabilan sistem tenaga listrik merupakan bagian yang perlu untuk dijaga dalam operasi sistem tenaga. Kestabilan sistem tenaga adalah kemampuan sistem yang memungkinkan sistem tersebut untuk tetap berada pada kondisi dalam batas operasi yang diinginkan pada keadaan normal atau abnormal di sistem tenaga.

Kestabilan sistem tenaga listrik diklasifikasikan berdasarkan hal di bawah ini [7]:

a. Sifat alami dari ketidakstabilan yang dihasilkan terkait dengan parameter sistem utama dimana ketidakstabilan diamati.

b. Ukuran gangguan di anggap menunjukkan metode perhitungan dan prediksi ketidakstabilan yang paling sesuai.

c. Proses, divais dan rentang waktu yang harus diambil untuk menjadi pertimbangan dalam menetukan kestabilan.

Menurut IEEE definition and classification of power system stability, P. Khundur [20] kembali mengklasifikasikan kestabilan sistem tenaga kedalam tiga bagian berdasarkan faktor konstribusi yang menyebabkan ketidakstabilan, seperti yang diperlihatkan pada Gambar 1 .

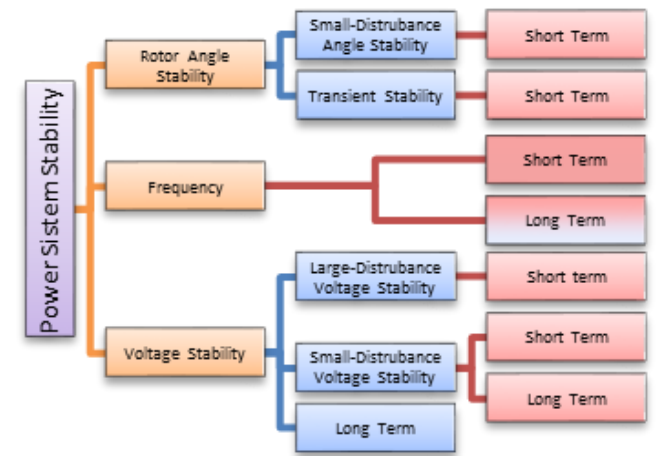

Gambar 1. Klasifikasi Stabilitas Sistem Tenaga Listrik [20]
Kestabilan tegangan digambarkan sebagai kemampuan suatu sistem tenaga untuk mempertahankan tegangan stabil di semua bus dalam sistem setelah mengalami gangguan dari kondisi operasi awal yang diberikan. Kestabilan tegangan bertujuan untuk mempertahankan keseimbangan antara permintaan beban dan pasokan beban. Seperti yang terlihat pada Gambar 1, kestabilan tegangan dapat di subkategorikan menjadi dua: kestabilan tegangan gangguan besar dan gangguan kecil dan mungkin dalam jangka panjang dan jangka pendek.

\subsection{Kestabilan tegangan}

Untuk Kestabilan tegangan merupakan salah satu faktor pada kestabilan sistem tenaga listrik. Kestabilan tegangan adalah kemampuan sistem untuk tetap menjaga nilai tegangan pada seluruh bus dalam batas operasi normal akibat terjadinya gangguan [7, 21]. Kestabilan tegangan terbagi menjadi dua yaitu kestabilan tegangan akibat gangguan besar, seperti kesalahan sistem, pelepasan generator atau kontijengsi pada jaringan dan akibat gangguan kecil yang bersifat lokal, misalnya perubahan kenaikan beban di sistem. Sehingga keadaan tersebut membuat sistem harus kembali dalam keadaan stabil. Berdasarkan gangguan yang terjadi pada kestabilan tegangan yang menyebabkan ketidakstabilan tegangan (voltage instability) terdapat rentang waktu dari beberapa detik sampai sepuluh menit seperti yang dilukiskan oleh Taylor [11] pada Gambar 2 dibawah ini:

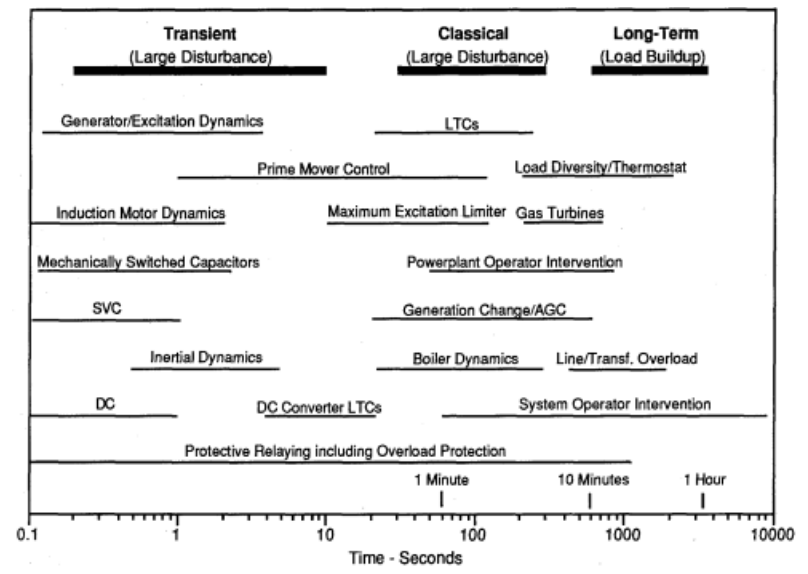

Gambar 2. Klasifikasi rentang waktu untuk fenomena kestabilan tegangan [11] 


\subsection{Under Voltage Load Shedding}

Under-Voltage Load Shedding (UVLS) merupakan suatu mekanisme pelepasan beban akibat tegangan sistem yang rendah dibawah batas tolenransi $-10 \%$ dari nilai nominalnya [22-23]. Sehingga kondisi tersebut dapat mengganggu kestabilan sistem tenaga listrik yang menyebabkan jatuhnya tegangan (voltage collaps) dan memungkinkan terjadinya pemadaman total (blackout) pada sistem. UVLS merupakan suatu skema proteksi yang bertujuan untuk melepas beban pada transformator distribusi agar tegangan sistem dapat naik ke kondisi normal.

Pelepasan beban pada transformator distribusi dengan skema UVLS memiliki beberapa tahapan. Hal ini mempertimbangkan kondisi beban transformator distribusi. Adapun pertimbangan tersebut meliputi dua aspek yaitu:

1) Aspek Teknis

a) UVLS perlu mempertimbangkan level tegangan sistem minimum pada pembangkit lain.

b) Lamanya waktu pembangkit dapat bertahan saat tegangan sistem turun secara terus menerus.

c) Kemampuan exciter pembangkit terlemah.

2) Aspek Non Teknis.

Karena UVLS mengharuskan untuk melakukan pemadaman disisi konsumen, maka sangat penting mempertimbangkan konsumen mana yang harus dipadamkan. Konsumen dengan tingkat prioritas yang tinggi harus dijaga kontinuitas penyaluran daya listrik.

Desain dari pelepasan beban harus "robust". UVLS harus mencakup banyak dan tidak terlalu sensitive. Oleh karena itu, ada dua langkah pertahanan system tenaga terhadap insiden yang mungkin memicu ketidakstabilan yang disebabkan oleh system yang yang mengalami gangguan dan beroperasi lebih dekat dengan batas stabilitas [24-25]:

- Dalam mengamati margin suatu sistem keamanan dilakukan tindakan preventif untuk mempertimbangkan kemungkinan kontigensi yang berbeda kemudian melakukan tindakan tepat sebagai solusi untuk mempertahankan margin sistem.
- Demi meminimalisir kemungkinan adanya resiko kejadian yang lebih parah, maka perlu dillakukan tindakan correctively dengan memanfaatkan aplikasi perbaikan secara otomatis dengan skema perlindungan.

Filosofi dari UVLS adalah bahwa setiap kali sistem terganggu, akan menyebabkan kondisi penurunan tegangan di bawah tingkat pra-dipilih untuk jangka waktu tertentu yang telah ditentukan sebelumnya, ketika beban yang dipilih harus dilepas [26]. Tujuan dari UVLS untuk mengembalikan keseimbangan daya dalam system, untuk mencegah tegangan runtuh dan mengatur masalah tegangan yang berada dalam wilayah lokal daripada menyebar ke daerah lain [27].

\subsection{Double Fed Induction Generator (DFIG)}

DFIG memiliki beberapa keunggulan diantaranya operasi variabel kecepatan untuk mendapatkan daya maksimum yang diektraksi dari angin, faktor daya yang dapat disesuaikan, efisiensi yang lebih baik, kemampuan untuk mengontrol daya reaktif tanpa dukungan kapasitif dan rating konverter yang lebih kecil [28-31].

Tenaga mekanik dari turbin angin diubah oleh DFIG yang dikirimkan kesistem dari belitan stator dan rotor [32]. DFIG terhubung ke turbin angin melalui gearbox dan konverter sumber tegangan kembali ke belakang [33]. Gearbox merupakan perangkat yang sangat penting untuk mengontrol keragaman berbagai kecepatan antara rotor dan generator. Gulungan stator dari DFIG dan sisi lain konverter yang memasok rotor terhubung ke sistem tenaga. Tegangan dijaga pada frekuensi konstan sedangkan besarnya dikendalikan dengan mengatur fluks stator generator.

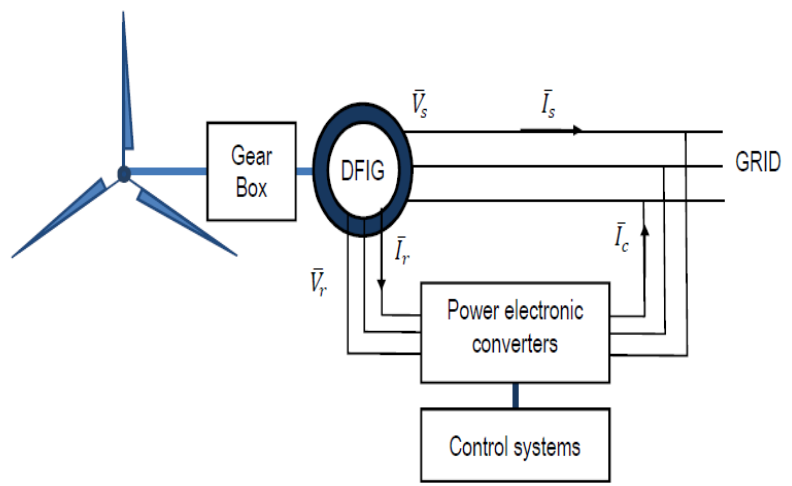

Gambar 3. Konfigurasi turbin Angin DFIG 


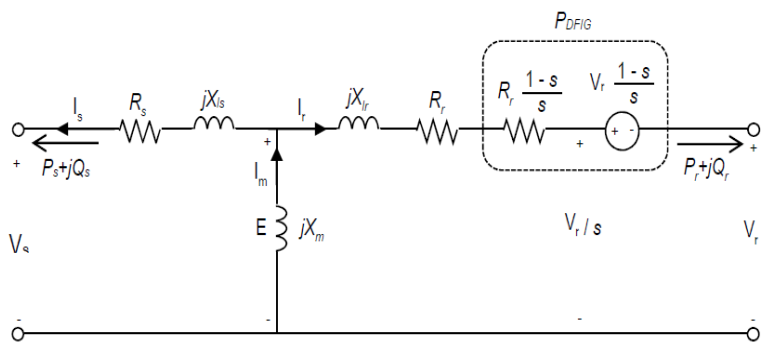

Gambar 4. Rangkaian Ekuivalen DFIG ${ }^{[32]}$

Konfigurasi teknologi turbin angin DFIG ditunjukkan secara skematik pada Gambar 3 dan Gambar 4 menampilkan rangkaian ekuivalen DFIG. Adapun perbandingan kecepatan dinamis fluks stator dan rotor dari jaringan dinamis dan system kontrol konverter yang memisahkan generator dari grid; oleh karena itu, persamaan elektrik steady state dengan mempertimbangkan DFIG yaitu [34]:

$v_{d s}=-r s i_{d s}+\left[\left(\chi_{s}+\chi_{m}\right) i_{q s}+\chi_{m} i_{q r}\right]$

$v_{q s}=-r_{s} i_{q s}-\left[\left(\chi_{s}+\chi_{m}\right) i_{d s}+\chi_{m} i_{d r}\right]$

$v_{d r}=-r_{R} i_{d r}+\left(1-\omega_{m}\right)\left[\left(\chi_{R}+\chi_{m}\right) i_{q r}+\chi_{m} i_{q s}\right]$

$v_{q r}=-r_{R} i_{d r}+\left(1-\omega_{m}\right)\left[\left(\chi_{R}+\chi_{m}\right) i_{q r}+\chi_{m} i_{d s}\right]$

Kemudian daya aktif dan reaktif dikirim ke grid menjadi:

$$
\begin{aligned}
& P=v_{d s} i_{d s}+v_{q s} i_{q s}+v_{d c} i_{d c}+v_{q c} i_{q c} \\
& Q=v_{d s} i_{d s}-v_{q s} i_{q s}+v_{d c} i_{d c}-v_{q c} i_{q c}
\end{aligned}
$$

\section{Metodologi Penelitian}

Penelitian ini melakukan perancangan skema under voltage load shedding menggunakan metode analisis sensitivitas dinamis pada sistem interkoneksi Sulselrabar data yang di ambil adalah data kelistrikan yang berasal dari PT. PLN (persero) UPB-UPT Wilayah Makassar.

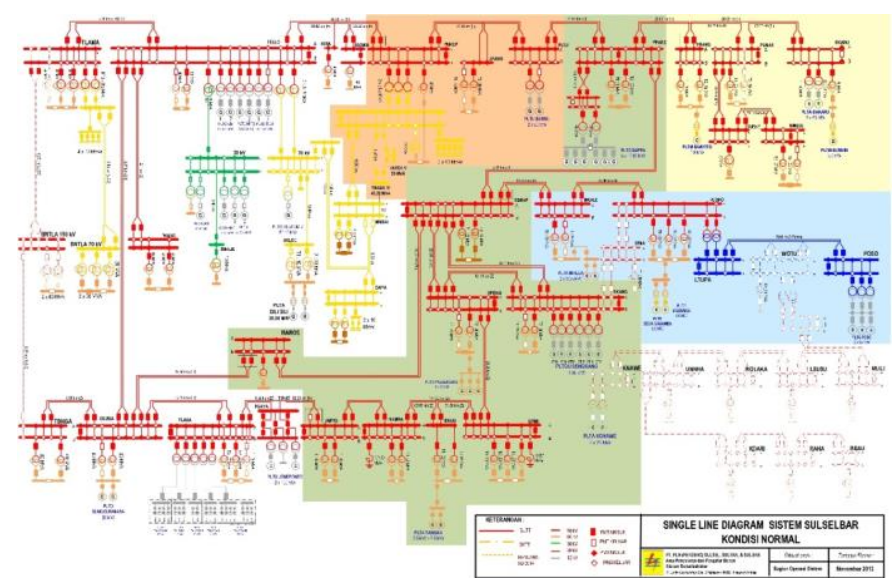

Gambar 5.Single line diagram interkoneksi Sulselrabar [35]

Alur yang digunakan dalam dalam perancangan UVLS ditunjukkan pada Gambar 6 sebagai berikut:

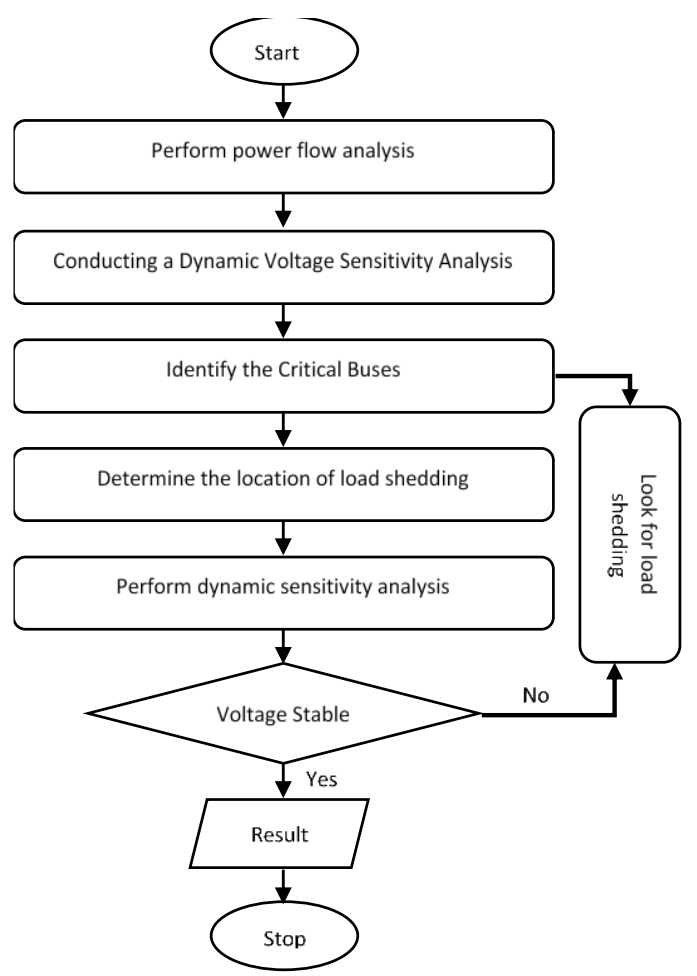

Gambar 6. Flowchart under voltage load shedding

\section{Hasil dan Simulasi}

\subsection{Sebelum masuknya Integrasi PLTB}

Simulasi awal yang dilakukan adalah simulasi dimana, PLTB Sidrap dan Jeneponto belum terintegrasi pada sistem interkoneksi Sulselrabar namun diberikan perlakukan gangguan pada kondisi tersebut. Simulasi gangguan terjadi pada bus Tello dan Pangkep pada $t=0.01$ detik. 
Gambar 7 menunjukkan profil tegangan saat disimulasikan gangguan antara bus Tello dan bus Pangkep dengan interval 0:01 detik. Hasil penelitian menunjukkan bahwa beberapa daerah memiliki tegangan di bawah 0.9 p.u, ini menunjukkan bahwa sistem menjadi tidak stabil namun tidak menyebabkan voltage collapse.

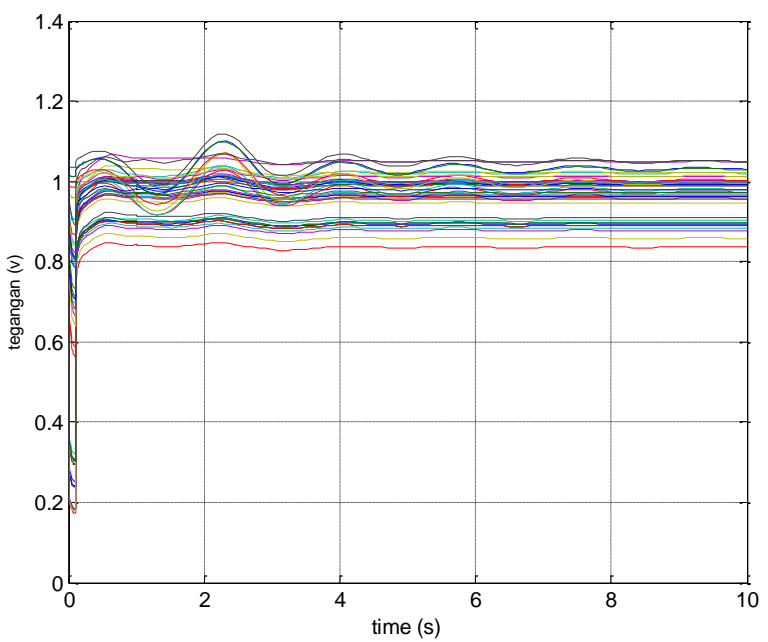

Gambar 7. Simulasi stabilitas tegangan setelah terjadinya gangguan sebelum integrasi PLTB

\subsection{Setelah masuknya Integrasi PLTB}

Gambar 8 menunjukkan penurunan tegangan / collapse di beberapa daerah dalam kondisi setelah integrasi PLTB Sidrap dan Jeneponto ketika terjadi gangguan pada bus antara Pangkep dan Tello. Hal ini dapat dilihat dari grafik bahwa tegangan pada bus Makale dan bus Palopo mengalami collapse 0 p.u pada $\mathrm{t}=1,8$ detik dan tidak dapat kembali ke keadaan stabil. Selanjutnya, tegangan pada bus La Tuppa juga mengalami penurunan tegangan hingga sekitar 0 , 52 p.u. Beberapa daerah di Makassar juga mengalami ketidakstabilan tegangan dengan magnitude diatas 0.8 p.u. Dengan banyak daerah yang menghadapi ketidakstabilan tegangan dan collapse, maka diperlukan load shedding.

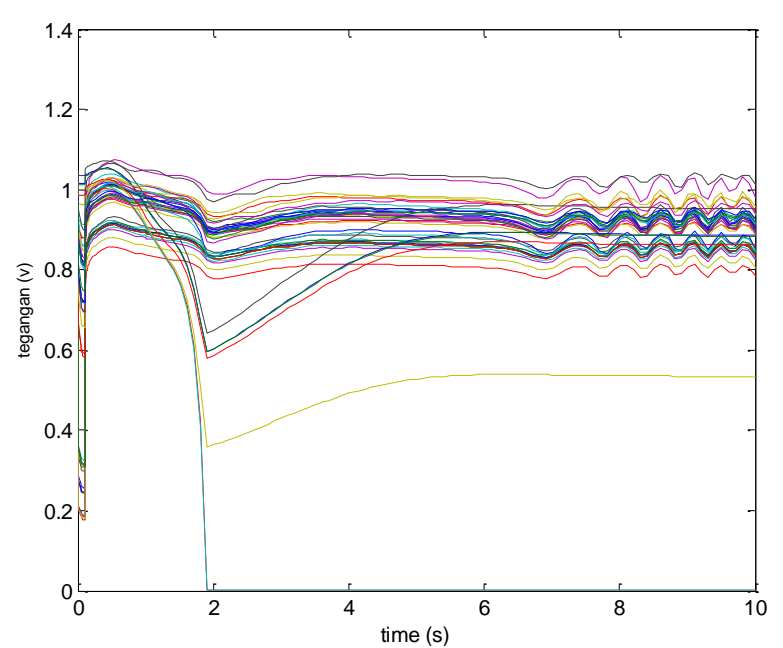

Gambar 8. Simulasi stabilitas tegangan setelah terjadinya gangguan dan setelah masuknya integrasi PLTB Jeneponto dan Sidrap

4.3. Simulasi tegangan setelah load shedding pada bus Makale dan Palopo

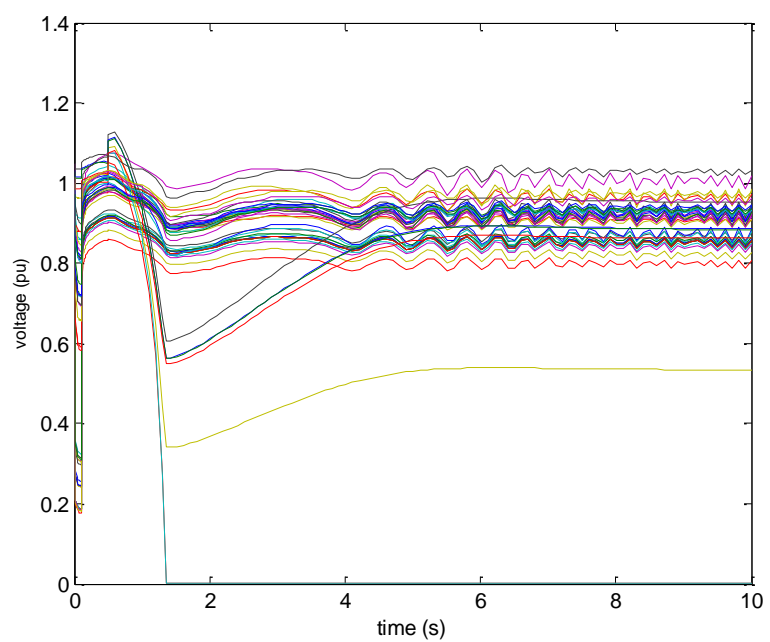

Gambar 9. Simulasi stabililitas tegangan dengan integrasi PLTB Sidrap dan Jeneponto setelah gangguan dan load shedding di Palopo dan Makale

Gambar 6 mensimulasikan kondisi tegangan dengan integrasi PLTB Sidrap dan Jeneponto setelah gangguan dan load shedding di Palopo dan Makale. Ini jelas menunjukkan bahwa dengan load shedding di bus Makale dan Palopo, tegangan di beberapa daerah tidak dapat kembali pulih pada kondisi yang stabil. Oleh karena itu, diperlukan lokasi lain untuk load shedding.

4.4. Simulasi tegangan setelah load shedding pada bus Makale, Palopo, dan Poso

Sejak load shedding di bus Palopo dan Makale tidak dapat menstabilkan sistem, maka perlu load shedding lagi. Gambar 10 menunjukkan grafik 
simulasi tegangan setelah load shedding di bus Makale, Palopo dan Pos, Namun tetap tidak dapat menstabilkan sistem.

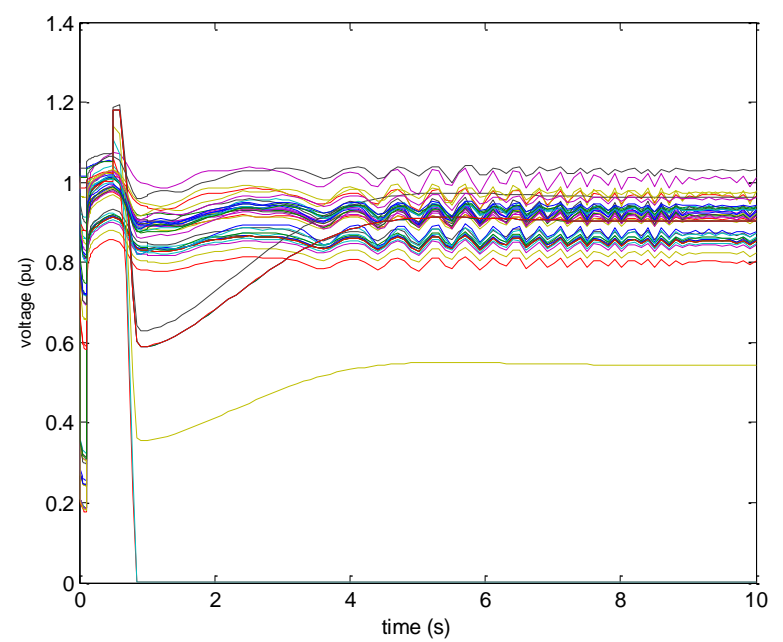

Gambar 10. Simulasi stabilitas tegangan dengan integrasi PLTB Jeneponto dan Sidrap setelah gangguan dan load shedding di Palopo, Makale dan Poso

4.5. Simulasi tegangan setelah load shedding pada bus Makale, Palopo dan Latuppa

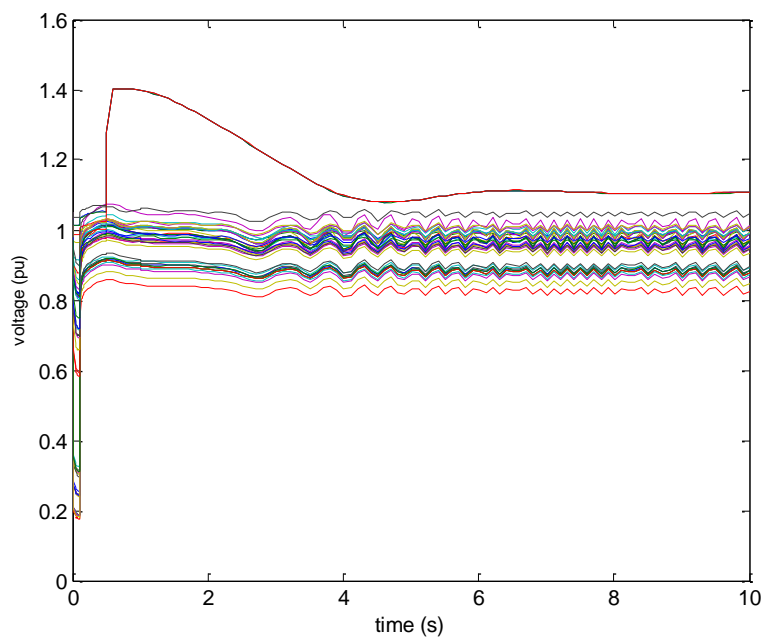

Gambar 11. Simulasi stabilitas tegangan dengan integrasi PLTB Jeneponto dan Sidrap setelah gangguan dan load shedding di Palopo, Makale dan Latuppa

Gambar 11 menunjukkan perbaikan tegangan setelah load shedding di bus Makale, Palopo dan Latuppa. Tegangan di bus Makale, Palopo dan Latuppa mampu pulih ke atas batas stabilitas, namun skema load shedding ini menyebabkan masalah lain, yaitu kondisi tegangan sementara. Pada bus Poso yang tegangannya pada $\mathrm{t}=0.6$ menjadi 1.4 p.u kemudian turun menjadi $1.1 \mathrm{p} . \mathrm{u}$ pada $\mathrm{t}=5.6$ detik.

\section{Kesimpulan}

Penelitian ini dilakukan di sistem tenaga interkoneksi Sulawesi Selatan mengingat integrasi pembangkit tenaga angin di daerah Sidrap dan Jeneponto. Studi ini pertama menilai penurunan tegangan sebelum dan sesudah integrasi PLTB. Ini menunjukkan bahwa dengan integrasi PLTB, saat terjadi gangguan antara bus Tello dan Palopo, tegangan di bus Makale, Palopo dan Latuppa ambruk. Setelah beberapa kali simulasi, ditemukan bahwa load shedding di bus Makale, Palopo dan Latuppa paling optimal sehingga kondisi stabilitas tegangan dapat kembali ke kondisi normal walaupun profil tegangan sementara terjadi di Bus Poso.

\section{Referensi}

[1] Kementrian ESDM Republik Indonesia, "PLTB Sidrap 70 MW Siap Dibangun," Direktorat Jendral Energi Baru Terbarukan dan Konservasi Energi (EBTKE), 2016.

[2] Situs Resmi Kabupaten Jeneponto, "Rapat Koordinasi Pembangunan Energi Terbarukan PLTB (Pembangkit Listrik Tenaga Bayu)," Jeneponto, 2015.

[3] Ardiaty Arief, M. Bachtiar N, Z. Y. Dong and M. Arief, "Under Voltage Load Shedding Incorporating Bus Participation Factor," IPEC 2010.

[4] Z. Y. Dong, "Power System Dynamics and Stability, reference note For ME course on Power System Dynamics and Stability," UQ Publisher, 2007.

[5] Z. Y. Dong and P. Zhang, "Emerging Tecniques in Power System Analysis”, Springer, 2009.

[6] M. Klaric, I. Kuzle, and S. Tesnjak, "Example of Under Voltage Load Shedding Implementation," in IEEE AFRICON Conference, Windhoek, Namibia, 26-28 September, 2007, pp. 1-6.

[7] P. Kundur, "Power System Stability and Control," New York: McGraw-Hill, 1994.

[8] Y. Mansour and C.Canizares, “Voltage Stability," in Power System Stability and Control, L. L. Grigsby, Ed. Boca Raton: Taylor and Francis Group, 2007.

[9] Agus R. Utomo and Dielita A. Malau, "Analisis Under Voltage load shedding Berdasarkan Nilai Sensitivitas Bus dan Daya Reaktif pada PT. PLN (Persero) APB DKI Jakarta \& Banten," Universitas Indonesia, Depok, 2014.

[10] H. G. Sarmiento, R. Castellanos, G. Pampin, G. Villa, and M. Mirabal, "Revisiting Undervoltage Load Shedding Schemes: A step by step approach," in Proc. IEEE/PES Transmission and Distribution Conference and Exposition, Chicago, USA, 21-24 april, 2008

[11] C. W Taylor, "Concepts of Undervoltage Load Shedding for Volttage Stability," IEEE Transactions on Power Delivery, vol. 7, pp. 480-488, 1992.

[12] Ardiaty Arief, M. Bachtiar Nappu, Marcus Gallagher, and Z. Y. Dong, "Under Voltage Load Shedding Utilizing Trajectory Sensitivity to Enhance Voltage Stability," in IEEE Power Engginering Conference (AUPEC), $21^{\text {st }}$ Australasian Universities, Brisbane, QLD, Australia, 2011. 
[13] Ardiaty Arief, Z. Y. Dong, M. Bachtiar Nappu and M. Gallagher. "Under Voltage Load Shedding in Power System with Wind Turbine-driven Doubly Fed Induction Generators," Electrical Power Systems Research, vol. 96, pp. 91-100, 3// 2013.

[14] M. Klaric, I. Kuzle, and S. Tesjnjak, "Under Voltage Load Shedding using Global Voltage Collapse Index," in IEEE PESPower Systems Conference and Exposition, New York, USA, 10-13 October, 2004, pp. 453-459, vol. 1.

[15] C. M. Affonso, L. C. P. da Silva, F. G. M. Lima, and S. Soares, "MW and MVar Management on Supply and Demand Side for Meeting Voltage Stability Margin Criteria," IEEE Transactions on Power Systrem, vol. 19, pp.1538-1545, 2004

[16] R. Balanathan, N. C. Pahalawaththa, U. D Annakkage, and P. W. Sharp, "Undervoltage Load Shedding to Avoid Voltage Instability," IEE Proceedings Generation, Transmission and distribution, vol. 145, pp. 175-181, 1998.

[17] R. Balanathan, N. C. Pahalawaththa, and U. D Annakkage, "A Strategy for Undervoltage Load Shedding in Power System," in Proceedings International conference on Power System Technology, POWERCON Beijing, China, 18-21 August, 1998, pp.1494-1498 vol. 2 .

[18] T. Amraee, A.M. Ranjibar, B. Mozafari, and N. Sadati, "An Enchanced Under-Voltage load Shedding Scheme to Provide Voltage Stability," Electric power Systems Research, vol. 77, pp. 1038-1046, 2007.

[19] C. Moors, D. Lefebvre, and T. Van Custem, "Design of Load Shedding Schemes Againts Voltage Instability, " in IEER Power Engineering SocietyWinter Meeting, Singapore, 23-27 January, 2000, pp. 1495-1500, vol. 2 .

[20] P. Kundur, Paserba, Jhon., dkk. "Definition and Classification of Power System Stability IEEE/CIGRE Joint Task Force on Stability Terms and Definitions," IEEE Transactions on Power Systems, vol. 19, pp. 1387-1401, 2004.

[21] E. Dedy Brian. "Analisis Kestabilan Tegangan Pada Sistem Kelistrikan Subsistem Tanjungjati," Universitas Diponegoro, Semarang. 2016

[22] Tim Penyusun PLN.’Pedoman dan Petunjuk Sistem Proteksi Transmisi dan Gardu Induk Jawa Bali," PT. PLN (Persero), Jakarta, 2013.

[23] Tim ESDM. "Aturan Jaringan Sistem Tenaga Listrik Sulawesi," PT. PLN (Persero) UPB Sulselrabar, Makassar, 2015.

[24] C. Moors, D. Lefebvre, and T. Van Cutsem, "Design of Load Shedding Schemes Against Voltage Instability," in IEEE Power Engineering Society Winter Meeting, Singapore, 23-27 January, 2000, pp. 1495-1500, vol. 2 .

[25] D. Lefebvre, S. Bernard, and T. Van Cutsem, "Undervoltage Load Shedding Scheme for the HydroQuebec System," in IEEE Power Engineering Society
General Meeting, Denver, Colorado, USA, 6-10 June, 2004, pp. 1619-1624 Vol.2.

[26] M. Begovic, D. Fulton, M. R. Gonzalez, J. Goossens, E. A. Guro, R. W. Haas, C. F. Henville, G. Manchur, G. L. Michel, R. C. Pastore, J. Postforoosh, G. L. Schmitt, J. B. Williams, K. Zimmerman, and A. A. Burzese, "Summary of "System Protection and Voltage Stability"," IEEE Transactions on Power Delivery, vol. 10, pp. 631-638, 1995.

[27] C. J. Mozina, "Undervoltage Load Shedding," in 60th Annual Conference for Protective Relay Engineers Texas, USA, 27-29 March, 2007, pp. 16-34.

[28] E. Vittal, M. O'Malley, and A. Keane, "A Steady-State Voltage Stability Analysis of Power Systems With High Penetrations of Wind," IEEE Transactions on Power Systems, vol. 25, pp. 433-442, 2010.

[29] H. Nian, Y. Song, P. Zhou, and Y. He, "Improved Direct Power Control of a Wind Turbine Driven Doubly Fed Induction Generator During Transient Grid Voltage Unbalance," IEEE Transactions on Energy Conversion, vol. 26, pp. 976-986, 2011.

[30] B. A. Chen, T. K. Lu, Y. Y. Hsu, W. L. Chen, and Z. C. Lee, "An Analytical Approach to Maximum Power Tracking and Loss Minimization of a Doubly Fed Induction Generator Considering Core Loss," IEEE Transactions on Energy Conversion, vol. 27, pp. 449456, 2012.

[31] H. Xu, J. Hu, and Y. He, "Operation of Wind-TurbineDriven DFIG Systems Under Distorted Grid Voltage Conditions: Analysis and Experimental Validations," IEEE Transactions on Power Electronics, vol. 27, pp. 2354-2366, 2012.

[32] C. H. Liu and Y. Y. Hsu, "Effect of Rotor Excitation Voltage on Steady-State Stability and Maximum Output Power of a Doubly Fed Induction Generator," IEEE Transactions on Industrial Electronics, vol. 58, pp. 1096-1109, 2011.

[33] C. Chompooinwai, C. Yingvivatanapong, K. Methaprayoon, and W. J. Lee, "Reactive Compensation Techniques to Improve the Ride-Through Capability of Wind Turbine During Disturbance," IEEE Transactions on Industry Applications, vol. 41, pp. 666-672, 2005.

[34] F. Milano, Power System Analysis Toolbox, 2005

[35] Bagian Operasi Sistem, Single Line Diagram Sistem Sulselbar, PT. PLN (Persero) SULSEL, SULTRA \& SULBAR Unit Pengaturan Beban Sulserabar. Makassar. 2016. 